\title{
Efeitos colaterais relacionados a suplementos termogênicos que contém sinefrina
}

\author{
Side effects related to thermogenic supplements containing symphine \\ Efectos secundarios relacionados con los suplementos termogénicos que contienen sinfina
}

\author{
Daniele de Araújo Moysés \\ ORCID: https://orcid.org/0000-0001-6956-1381 \\ Universidade Federal do Pará, Brasil \\ E-mail: quimica.dani@gmail.com \\ Ana Rafaela Ferreira Antunes \\ ORCID: https://orcid.org/0000-0001-8456-1523 \\ Escola Superior da Amazônia, Brasil \\ E-mail: rafaferreiraantunes@gmail.com \\ Danubia de Nazaré Amador dos Santos \\ ORCID: https://orcid.org/0000-0001-5882-2064 \\ Escola Superior da Amazônia, Brasil \\ E-mail: danubia.amador2014@gmail.com \\ Regianne Maciel dos Santos Correa \\ ORCID: https://orcid.org/0000-0002-9837-4304 \\ Universidade Federal do Pará, Brasil \\ E-mail: regianne@ufpa.br \\ Natasha Costa da Rocha Galucio \\ ORCID: https://orcid.org/0000-0003-4923-1478 \\ Escola Superior da Amazônia, Brasil \\ E-mail: natashagalucio@gmail.com \\ Tatiene Vieira Gonçalves \\ ORCID: https://orcid.org/0000-0003-0617-5242 \\ Escola Superior da Amazônia, Brasil \\ E-mail: tatiene123@gmail.com \\ Eliel Barbosa Teixeira \\ ORCID: https://orcid.org/0000-0001-5102-1811 \\ Universidade Federal do Pará, Brasil \\ E-mail: elielcn2015@gmail.com \\ Marcelli Geisse de Oliveira Prata da Silva \\ ORCID: https://orcid.org/0000-0002-3999-5565 \\ Universidade Federal do Pará, Brasil \\ E-mail:mgso@ufpa.br \\ Andreza Abreu Rocha \\ ORCID: https://orcid.org/0000-0001-9538-1528 \\ Escola Superior da Amazônia, Brasil \\ E-mail: andreza.aaj@gmail.com \\ Joseneide Gonçalves da Costa \\ ORCID: https://orcid.org/0000-0002-5476-0115 \\ Escola Superior da Amazônia, Brasil \\ E-mail: josycosta28@hotmail.com \\ Ernande Roberto do Nascimento Medeiros \\ ORCID: https://orcid.org/0000-0001-5337-1276 \\ Escola Superior da Amazônia, Brasil \\ E-mail: ernade678@gmail.com \\ Wanderley da Costa Silva \\ ORCID: https://orcid.org/0000-0003-4393-2775 \\ Universidade Federal do Pará, Brasil \\ E-mail: wandosc05@gmail.com \\ Valdicley Vieira Vale \\ ORCID: https://orcid.org/0000-0001-6570-4875 \\ Escola Superior da Amazônia, Brasil \\ E-mail: valdicleyvale@gmail.com
}

\section{Resumo}

Os Suplementos Alimentares (SA) são largamente utilizados por esportistas e praticantes de atividades físicas, como forma de complementação da dieta, seja para ganho, perda de peso ou outros objetivos específicos. Os Termogênicos, nesse caso, são compostos de substâncias que têm a capacidade de acelerar o metabolismo, oferecendo maior queima de calorias e reduzindo o apetite. Por outro lado, podem conter substâncias, como a Sinefrina, que pode causar danos à saúde. Desse modo, a presente pesquisa tem como objetivo investigar a composição química de suplementos 
termogênicos que contém sinefrina. A pesquisa foi dividida em dois momentos, sendo analisado, primeiramente, o rótulo desses suplementos, coletados no sítio da internert e posteriormente, foi feita uma revisão de literatura sistemática, na qual foram selecionados artigos científicos, no período de 2010 a 2019, dentro da base de dados da SciELO, PubMed, Bireme, Google Acadêmico, e LILACS, utilizando os descritores: Suplementos alimentares/ food suplements; Sinefrina/ synephrine; Emagrecimento/ slimming; Termogênico/ thermogenic. Para atender aos critérios de inclusão foram escolhidos artigos científicos e dissertações, apresentando-se na íntegra, isto é, texto completo, sendo disponibilizados no idioma português e inglês, que estavam de acordo com o tema proposto. O estudo foi fundamentado em abordagens sobre a influência dos suplementos na qualidade de vida, termogênico à base de sinefrina e os efeitos colaterais de tais produtos. Como resultados, a pesquisa concluiu que a sinefrina, sendo semelhante à efedrina, desenvolve efeitos sobre o sistema cardiovascular, podendo gerar casos de aumento de pressão arterial, aumento da frequência cardíaca, arritmias e acidente vascular cerebral (AVC), principalmente, quando associada à cafeína. Alguns estudos relataram também, que a sinefrina pode ocasionar problemas no fígado e nos rins. Portanto, conclui-se que tais compostos quando não utilizados de forma correta e sem orientação devida, pode causar sérios danos à saúde.

Palavras-chave: Suplementos alimentares; Sinefrina; Termogênicos; Emagrecimento.

\begin{abstract}
Food Supplements (SA) are widely used by athletes and practitioners of physical activities, as a way to complement their diet, whether for gain, weight loss or other specific goals. Thermogenics, in this case, are composed of substances that have the ability to speed up metabolism, offering greater calorie burning and reducing appetite. On the other hand, they may contain substances, such as Synephrine, which can harm health. Thus, this research aims to investigate the chemical composition of thermogenic supplements containing synephrine. The research was divided into two stages. Firstly, the label of these supplements was analyzed, collected on the internet site, and later, a systematic literature review was carried out, in which scientific articles were selected, from 2010 to 2019 , within the database from SciELO, PubMed, Bireme, Google Scholar, and LILACS, using the descriptors: Food supplements/ food supplements; Synephrine/synephrine; Slimming/slimming; Thermogenic/ thermogenic. For meeting the inclusion criteria, scientific articles and dissertations were chosen, presenting themselves in full, that is, full text, being made available in Portuguese and English, which were in accordance with the proposed theme. The study was based on approaches to the influence of supplements on quality of life, thermogenic synephrine-based and the side effects of such products. As a result, the research concluded that synephrine, being similar to ephedrine, develops effects on the cardiovascular system, which can generate cases of increased blood pressure, increased heart rate, arrhythmias and stroke, especially when associated with caffeine. Some studies have also reported that synephrine can cause liver and kidney problems. Therefore, it is concluded that such compounds when not used correctly and without proper guidance, can cause serious damage to health.
\end{abstract}

Keywords: Food suplements; Synephrine; Thermogenics; Slimming.

\title{
Resumen
}

Los Complementos Alimenticios (SA) son ampliamente utilizados por deportistas y practicantes de actividades físicas, como una forma de complementar su dieta, ya sea para ganar, adelgazar u otros objetivos específicos. Los termogénicos, en este caso, están compuestos por sustancias que tienen la capacidad de acelerar el metabolismo, ofreciendo una mayor quema de calorías y reduciendo el apetito. Por otro lado, pueden contener sustancias, como la sinefrina, que pueden dañar la salud. Por lo tanto, esta investigación tiene como objetivo investigar la composición química de los suplementos termogénicos que contienen sinefrina. La investigación se dividió en dos etapas. En primer lugar, se analizó la etiqueta de estos suplementos, se recogió en el sitio de internet, y posteriormente se realizó una revisión bibliográfica sistemática, en la que se seleccionaron artículos científicos, de 2010 a 2019, dentro de la base de datos. de SciELO, PubMed, Bireme, Google Scholar y LILACS, utilizando los descriptores: Complementos alimenticios / complementos alimenticios; Sinefrina / sinefrina; Adelgazar / adelgazar; Termogénico / termogénico. Para cumpliendo con los criterios de inclusión, se eligieron artículos científicos y disertaciones, presentándose íntegramente, es decir, en texto completo, estando disponible en portugués e inglés, las cuales fueron acordes con la temática propuesta. El estudio se basó en enfoques sobre la influencia de los suplementos en la calidad de vida, basados en sinefrina termogénica y los efectos secundarios de dichos productos. Como resultado, la investigación concluyó que la sinefrina, al ser similar a la efedrina, desarrolla efectos sobre el sistema cardiovascular, lo que puede generar casos de aumento de la presión arterial, aumento de la frecuencia cardíaca, arritmias y accidentes cerebrovasculares, especialmente cuando se asocia con cafeína. Algunos estudios también han informado que la sinefrina puede causar problemas hepáticos y renales. Por tanto, se concluye que dichos compuestos, cuando no se utilizan correctamente y sin la debida orientación, pueden provocar graves daños a la salud.

Palabras clave: Suplementos alimenticios; Sinefrina; Termogénicos; Adelgazar.

\section{Introdução}

A busca pela qualidade de vida tem sido uma das práticas mais procuradas pela maioria da população e a tendência é 
que essa busca cresça cada vez mais (Miranda et al., 2016). Contudo, mesmo que seja uma tendência, uma pesquisa realizada pela Organização Mundial da Saúde (OMS), revelou que 47\% da população brasileira não pratica o mínimo de atividade física recomendado, que é de 150 minutos por semana (OMS, 2018). Por outro lado, de acordo a pesquisa realizada pela Associação Internacional de Fomento ao Universo de Saúde e Exercícios (IHRSA) (2018), no Brasil, há mais de 34 mil academias, sendo considerado, o segundo país, do mundo, com maior concentração de empresas do ramo. Diante disso, ao mesmo passo que o número de academias cresce no Brasil, as opções alimentares e, principalmente, o consumo de suplementos, também cresce. Isso se comprova pelos números informados pela Associação Brasileira de Produtos Nutricionais (ABENUTRI), em 2018, a qual revelou que só o setor de Sport Nutrition faturou cerca de $\mathrm{R}$ \$2,24 bilhões, tendo um crescimento de 12\% em relação a 2017; ainda de acordo com a instituição, em 2019, esse avanço foi para 15\%. Dentre os produtos mais consumidos, destacamse os proteicos, representando cerca de 60\% das vendas (Ponsoni, 2019).

De acordo com Pacheco (2017), os Suplementos Alimentares (SA) são largamente utilizados por esportistas e praticantes de atividades físicas, como forma de complementação da dieta, seja para ganho, perda de peso ou outros objetivos específicos. Para esses produtos, a Agência Nacional de Vigilância Sanitária (ANVISA), estabeleceu a RDC no 18, de 27 de abril de 2010, que dispõe sobre os alimentos para atletas, classificando-os: suplementos hidroeletrolíticos, energéticos, proteicos, para substituição parcial de refeições, de creatina e de cafeína (Brasil, 2010). Andressa (2015), complementa que existe uma classe de suplementos chamada de Termogênicos. A autora os define como compostos de substâncias que têm a capacidade de acelerar o metabolismo, oferecendo maior queima de calorias e reduzindo o apetite. De acordo com Peçanha et al. (2017), os termogênicos são os suplementos mais consumidos, pois, além de serem comercializados facilmente em mercados, farmácias e lojas de suplementação para atletas, são também muito utilizados por pessoas que desejam acelerar a queima de gordura e consequentemente, reduzir peso.

Por conta disso, visando regulamentar a comercialização dos SA, a ANVISA criou a RDC no 243, de 26 de julho de 2018, a qual estabelece critérios para composição, qualidade, segurança e rotulagem dos SA, bem como para a atualização da lista de nutrientes, substâncias bioativas, enzimas e probióticos, limites de uso, alegações e rotulagem complementar de tais produtos, de modo a garantir a saúde dos consumidores. Destaca-se, dessa forma, uma das substâncias muito utilizadas na composição dos termogênicos, a Sinefrina. Segundo Beles (2014), essa substância está presente em pequena quantidade na casca da laranja; é uma substância alcaloídica, com efeitos termogênicos (aumento do metabolismo basal e maior queima de gordura) e lipolíticos (decomposição química de gorduras no organismo), os quais aumentam o metabolismo de produção de energia e a performance física. Contudo, se for administrada isoladamente, pode causar efeitos vasoconstritores, podendo assim, ocasionar um aumento de pressão arterial (PA).

Bacurau (2007), afirma que existem poucas informações científicas sobre o uso de suplementos e consequentemente, pode haver a falta de conhecimento por parte dos profissionais de saúde sobre os efeitos que esses produtos podem causar no organismo humano. Complementando com o autor, um estudo realizado por Costa et al. (2012) revelou que os SA nem sempre apresentam eficácia, sendo assim, grande parte da literatura científica levanta dúvidas quanto aos benefícios dos termogênicos, colocando um ponto de interrogação quanto a eficiência desses produtos e seus efeitos no organismo.

Partindo dessa premissa, surgiu o seguinte questionamento: "De que forma os Suplementos Alimentares (SA), que contém sinefrina, podem ocasionar efeitos adversos no organismo humano?” As hipóteses deste estudo são que, a sinefrina não desenvolve efeitos adversos sobre a PA, mas associada com a cafeína, há aumento nesse parâmetro, e que os termogênicos, a base de Sinefrina são mais saudáveis se neles conterem a quantidade de mg segura no produto. Considera-se esta pesquisa relevante, pois proporciona informações significativas sobre o consumo dos AS e sobre as reações adversas que podem causar no organismo, em virtude das substâncias que se fazem presente na composição dos mesmos. As informações aqui propostas podem conscientizar a população sobre as consequências do uso indiscriminado de SA sem orientação de um profissional da 
saúde.

\section{Metodologia}

\subsection{Tipo de abordagem}

A pesquisa foi dividida em dois momentos. No primeiro momento, foi analisado o rótulo dos SA, e no segundo momento, foi feito um estudo comparativo, por meio de revisão integrativa, analisando a composição dos suplementos em relação aos seus efeitos adversos. A revisão integrativa da literatura, de acordo com Sampaio e Mancini (2007), é uma pesquisa que permite reunir uma maior quantidade de resultados relevantes e, é geralmente estruturada após as publicações de variados estudos experimentais sobre determinado tema, para isso, a qualidade da fonte primária é levada em consideração.

\subsection{Procedimento de Coleta de Dados}

Foram verificadas um total de 10 amostras de suplementos, constituídos de sinefrina e/ou Citrus aurantium. As informações contidas nos rótulos de tais amostras foram retiradas no sítio da internet, utilizando a busca na opção "Shopping”, do Google, inserindo as palavras: "sinefrina", "emagrecimento" e "termogênico". A pesquisa dos suplementos foi realizada no período de abril e maio de 2020. Já a pesquisa integrativa, foi tirada de estudos primários relacionados ao tema em questão. Galvão e Pereira (2014) descrevem o estudo primário como sendo aquele nos quais os artigos científicos relatam os resultados de uma pesquisa em primeira mão. Desse modo, foram escolhidos artigos científicos na literatura de Farmácia, em Inglês e Português, selecionados dentro da base de dados da Scientific Eletronic Library Online (SciELO), Literatura Latino-americana e do Caribe em Ciências da Saúde (BIREME) e Sistema Online de Busca e Análise de Literatura Médica (MEDLINE), no período de 2010 a 2019. Os descritores utilizados foram verificados dentro da Biblioteca Virtual em Saúde, através das seguintes palavras-chave: suplementos alimentares/food suplements; sinefrina/synephrine; emagrecimento/slimming; Termogênico/thermogenic.

\subsubsection{Critérios de Inclusão e Exclusão}

Quanto aos critérios de inclusão, foram escolhidos 7 artigos científicos, apresentando-se na íntegra, isto é, texto completo, sendo disponibilizados no idioma português e inglês, publicados no período de 2010 a 2019 e que abordavam sobre a composição química de suplementos alimentares contendo sinefrina, analisando os possíveis efeitos colaterais. Foram excluídos da pesquisa artigos em idioma diferente do português e inglês, resumos, artigos publicados anteriormente à 2010 e artigos que não estavam dentro do tema proposto nesta pesquisa, ou seja, que não tratavam sobre a composição química de suplementos alimentares contendo sinefrina. Quanto aos suplementos, foram excluídos os que não continham, na descrição no sítio da internet, as informações completas do produto, isto é, que não apresentavam a composição e quantidade das substâncias utilizadas no mesmo.

\subsection{Aspectos Éticos}

Devido tratar-se de pesquisa que não utilizou dados de usuários em nenhum momento, pois os dados estavam nos artigos pesquisados, não houve necessidade de submeter ao Comitê de Ética em pesquisa, conforme Resolução no 466 de 12 de dezembro de 2012.

\subsection{Análise dos Dados}

A análise dos dados se deu por meio da análise das amostras coletadas e da leitura dos artigos, dos quais foram extraídas informações necessárias para atingir os objetivos da pesquisa. Os dados obtidos, tanto dos suplementos quanto dos artigos, foram informatizados em planilhas, no programa Microsoft Excel versão 2013. 


\section{Resultados e Discussão}

\subsection{Estudo Comparativo Baseado na Revisão da Literatura}

O estudo em questão buscou analisar o uso dos suplementos termogênicos à base de sinefrina e seus efeitos adversos na saúde do homem. Os resultados mais relevantes foram aqueles que mostraram o perigo que tais compostos podem acometer às pessoas que sofrem com algum tipo de problema cardíaco. A Sinefrina, nesse caso, mesmo isolada pode ocasionar aumento de PA e da frequência cardíaca. Quando associada à cafeína, esses riscos aumentam em virtude da sinergia entre ambas (Alves \& Capela, 2019). Isso revela a importância de se conhecer sobre os componentes presentes nos termogênicos, assim como, saber se o usuário se encontra no grupo de risco para consumo do mesmo. Em alguns suplementos verificados, constam informações que advertem os indivíduos com hipertensão a não consumir aquele produto. Além disso, constatou-se que, na composição destes, havia associação da sinefrina com cafeína (Lopes, 2016).

$\mathrm{Na}$ literatura levantada, observou-se que a maioria dos autores colocavam suas observações quanto ao acompanhamento profissional para fazer uso desses produtos, principalmente, em virtude dos efeitos que podem causar. Diante disso, apresenta-se os artigos selecionados para análise da temática, onde estão dispostos no quadro 2, identificando o nome do autor, ano, título e resultados.

Quadro 2: Artigos selecionados para análise da temática, identificando o nome do autor, ano, título e resultados.

\begin{tabular}{|c|c|c|}
\hline Autor(res) /Ano & Título & Resultados \\
\hline Kaefer (2014) & $\begin{array}{l}\text { Sinefrina: desenvolvimentoe validação de } \\
\text { método indicativo da estabilidade e } \\
\text { avaliação da toxicidade emextrato seco } \\
\text { de Citrus aurantium L. }\end{array}$ & $\begin{array}{c}\text { A pesquisa concluiu que as amostras verificadas de sinefrina, a partir } \\
\text { do extrato seco do Citrus aurantium, causam danos ao DNA e } \\
\text { diminuem a viabilidade celular }\end{array}$ \\
\hline Fagundes (2016) & $\begin{array}{c}\text { Análise toxicológica de suplementos } \\
\text { alimentares ecompostos emagrecedores } \\
\text { contendo salicina, efedrina, } p \text {-sinefrina e } \\
\text { cafeína }\end{array}$ & $\begin{array}{c}\text { Observou-se no estudo que o uso da cafeína contribui com a redução } \\
\text { de massa muscular (MM); já com a p-sinefrina, verificou-se redução } \\
\text { de massa corporal. Quanto aos efeitos, verificou-se degeneração } \\
\text { hidrópica, infiltrado inflamatório nos rins e nível considerável de } \\
\text { toxicidade. }\end{array}$ \\
\hline Do Nascimento et al. (2017) & $\begin{array}{c}\text { Nutracêuticos para emagrecimento: } \\
\text { uma revisão }\end{array}$ & $\begin{array}{l}\text { Observou-se que os nutracêuticos constituem fontes de compostos } \\
\text { naturaiscom propriedades antioxidantes, anti-inflamatórias, } \\
\text { hipoglicemiantes e anticarcinogênicas. São benéficos na redução dos } \\
\text { riscos provenientes das DCNT. }\end{array}$ \\
\hline Oliveira et al. (2017a) & $\begin{array}{c}\text { Consumo de suplementostermogênicos e } \\
\text { seus efeitos adversos por clientes de uma loja } \\
\text { de nutrição esportiva de } \\
\text { Fortaleza - CE. }\end{array}$ & $\begin{array}{c}\text { O estudo observou, quanto aos efeitos colaterais relacionados ao uso } \\
\text { desuplementos, que estes causam agitação, sudorese, tremor nas } \\
\text { mãos e aumento da temperatura corporal. Além disso, muitos } \\
\text { participantes não tinham orientaçãoadequada quanto ao uso dos } \\
\text { mesmos. }\end{array}$ \\
\hline Oliveira et al.(2017b) & $\begin{array}{l}\text { Laranja amarga (Citrus aurantium) como } \\
\text { coadjuvante no tratamento da obesidade }\end{array}$ & $\begin{array}{l}\text { Constatou-se que o produto possui substâncias capazes de agir sobre } \\
\text { o metabolismo do indivíduo, auxiliando de forma eficaz no } \\
\text { tratamento da obesidade, sem toxicidade relevante quando } \\
\text { empregado de forma isolada. Porém, carece a realização de mais } \\
\text { estudos que comprovem seus benefícios em longo prazo. }\end{array}$ \\
\hline Santos \& Ramos (2018) & $\begin{array}{l}\text { Avaliação do conhecimentoentre } \\
\text { praticantes de atividade física e } \\
\text { sedentários sobre os efeitos fisiológicos e } \\
\text { adversos dos suplementos termogênicos }\end{array}$ & $\begin{array}{c}\text { A pesquisa conclui que os praticantes de atividades físicas são os que } \\
\text { maisconhecem sobre o uso de termogênicos, porém consomem de } \\
\text { forma indiscriminada. Quanto aos efeitos adversos, verificou-se que } \\
\text { a insônia é o que mais prevalece no grupo estudado. }\end{array}$ \\
\hline Alves \& Capela (2019) & $\begin{array}{l}\text { Suplementos alimentares para } \\
\text { emagrecimento contendo sinefrina: riscos e } \\
\text { toxicidade }\end{array}$ & $\begin{array}{c}\text { O estudo verificou que os níveis de sinefrina presentes em vários } \\
\text { suplementos podem ser danosos para a saúde dos consumidores. } \\
\text { O risco cardiovascular dasinefrina é aumentado na presença de } \\
\text { cafeína. Os consumidores devem ser alertados para os níveis destes } \\
\text { compostos presentes nos suplementos. }\end{array}$ \\
\hline
\end{tabular}

Fonte: Autores. 
No estudo realizado por Kaefer (2014), os principais resultados da pesquisa foram a diminuição da viabilidade celular e os danos que a sinefrina causa no DNA. Embora seja considerada uma substância proveniente da laranja, deve-se levar em consideração seus riscos tóxicos. De acordo com Gindri et al. (2014), alguns estudos com extratos vegetais têm apresentado resultados com ação genotóxica, sendo necessário verificar, cientificamente, a segurança de certos produtos que são comercializados na medicina popular.

Aquino (2010) reforça também que tais riscos podem ocorrer de forma aguda e em longo prazo, causando complicações severas. Sendo assim, é de suma importância adotar medidas técnicas que possam identificar os níveis de toxicidade dos produtos que são comercializados como naturais ou fitoterápicos, de modo a assegurar a segurança e eficácia destes. A pesquisa de Fagundes (2016) comprovou os efeitos que a cafeína e a sinefrina causam no corpo. Tanto a cafeína quanto a sinefrina apresentaram resultados satisfatórios quanto à perda de peso, em contrapartida, quando associadas, a autora verificou que ambas apresentaram um comportamento tóxico considerável, ocasionando algumas alterações fisiológicas no organismo. Esse comportamento tóxico, observado no estudo da autora supracitada, está relacionado aos danos renais e hepáticos que a associação entre cafeína, sinefrina, efedrina e salicina, podem ocasionar. Desse modo, Schmitt (2012) enfatiza que o fígado é um dos órgãos mais suscetíveis aos efeitos tóxicos que essas substâncias proporcionam.

Na investigação feita por Oliveira et al. (2017a), as principais conclusões apresentadas foram com base nos efeitos colaterais relacionados ao uso de suplementos e que a maioria dos usuários destes, não tinham orientação adequada para consumi-los. Segundo essa pesquisa, o maior efeito colateral citado foi a insônia, seguidos da agitação, sudorese e tremor nas mãos. Tais efeitos puderam ser observados também, no estudo feito por Santos e Ramos (2018), em que as principais reações foram a insônia, a agitação e a ansiedade. Além do mais, dos 52 participantes da pesquisa, cerca de $65 \%$ destes faziam o uso sem a indicação de um profissional da saúde. Esta realidade é confirmada por Muraro e Saldanha (2016), ao relatarem que o uso indiscriminado dos suplementos é corriqueiro, mesmo com a ausência de uma evidência científica em relação à eficácia e segurança dos mesmos. Soma-se a isso, o fato desses produtos terem livre acesso em sua comercialização, bem como, a busca incessante por resultados estéticos mais ágeis.

Em se tratando da pesquisa feita por Oliveira et al. (2017b) foi verificado que a sinefrina não apresentou toxicidade, em doses elevadas. Além disso, verificou-se que possui substâncias que podem agir no metabolismo do usuário, contribuindo, de maneira eficaz, no tratamento da obesidade, sem risco de toxicidade quando administrada de forma isolada. Por outro lado, contrapondo-se a esse estudo, Alves e Capela (2019) relataram em suas investigações que os níveis de sinefrina, encontrados em vários suplementos, podem acarretar sérios danos à saúde dos consumidores, por conta dos efeitos estimulantes no Sistema Nervoso Central (SNC), cardiovascular e cerebrovascular, aumentando os níveis da PA e da frequência cardíaca, principalmente, quando associada à cafeína. Por todas essas razões, quanto ao uso de suplementos termogênicos, Do Nascimento et al. (2017) defendem o consumo de alimentos que sejam de origem vegetal, ou seja, aumentar o consumo de frutas, legumes, verduras, grãos integrais, peixes, aves e diminuir a ingestão de gorduras e frituras. Eles ressaltam também que manter hábitos alimentares saudáveis podem minimizar a ocorrência de doenças cardiovasculares, hepáticas, câncer, entre outros.

\subsection{Análise dos Suplementos Selecionados na Internet}

A composição e respectivas quantidades contidas na descrição dos suplementos, verificados no sítio da internet, discriminados pelos produtores ou distribuidores de tais produtos, isto é, que continham sinefrina/Citrus aurantium, foram descritos na tabela 1 . 
Tabela 1: Composição e quantidades contidas na descrição dos suplementos, discriminados pelos produtores ou distribuidores de tais produtos, que contém sinefrina/Citrus aurantium.

\begin{tabular}{|c|c|c|c|c|}
\hline Suplemento & $\begin{array}{l}\text { Sinefrina/ } \\
\text { Citrus aurantium/ } \\
\text { Quant. }\end{array}$ & $\begin{array}{c}\text { Dose } \\
\text { recomendada }\end{array}$ & $\begin{array}{l}\text { Ingredientes } \\
\text { adicionais/Quant. }\end{array}$ & Contra-indicação \\
\hline 1 & 60 cápsulas/ $250 \mathrm{mg}$ & 1 cápsula/dia & $\begin{array}{l}\text { Cafeína }-100 \mathrm{mg} \\
\text { Chá verde }-200 \mathrm{mg} \\
\text { Capsiate }-2,5 \mathrm{mg}\end{array}$ & $\begin{array}{c}\text { Pacientes sensíveis a cafeína ou com dificuldade } \\
\text { paradormir; portadores de dispepsia; pacientes } \\
\text { com uso de warfarina; mulheres grávidas, } \\
\text { lactantes e crianças. }\end{array}$ \\
\hline 2 & 30 cápsulas /1600mg & 1 cápsula/dia & r & $\begin{array}{l}\text { Grávidas, lactantes } \\
\text { e menores de 18anos. }\end{array}$ \\
\hline 3 & 30 cápsulas $/ 1000 \mathrm{mg}$ & 1 cápsula/ dia & Chá Verde $-700 \mathrm{mg}$ & Grávidas, lactantese menores de 18 anos. \\
\hline 4 & 60 cápsulas $/ 100 \mathrm{mg}$ & $\begin{array}{l}1 \text { cápsula } 2 \text { vezes/ } \\
\text { dia }\end{array}$ & $\begin{array}{l}\text { Faseolamina }-200 \mathrm{mg} \\
\text { Pholia Negra }-100 \mathrm{mg}\end{array}$ & $\begin{array}{c}\text { Pessoas comdiabetes; pessoascom } \\
\text { hipoglicemia;grávidas; lactantes; menores de } 18 \\
\text { anos. }\end{array}$ \\
\hline 5 & $\begin{array}{l}120 \text { cápsulas / } \\
300 \mathrm{mg}\end{array}$ & 1 cápsula/ dia & $\begin{array}{l}\text { Ioimbina }-5,4 \mathrm{mg} \\
\text { Cafeína }-100 \mathrm{mg}\end{array}$ & $\begin{array}{l}\text { Grávidas, lactantes,menores de } 18 \text { anos, } \\
\text { cardiopatas. }\end{array}$ \\
\hline 6 & $\begin{array}{l}60 \text { cápsulas / } \\
500 \mathrm{mg}\end{array}$ & $\begin{array}{l}1 \text { cápsula } 2 \text { vezes/ } \\
\text { dia }\end{array}$ & $\begin{array}{c}\text { Sinefrina em fruto } \\
\text { fresco }-0,1 \mathrm{mg} \\
\text { Sinefrina em fruto } \\
\text { seco }-1,76 \mathrm{mg} \\
\text { Sinefrina em extrato de fruto } \\
\text { seco }-15 \mathrm{mg}\end{array}$ & $\begin{array}{l}\text { Grávidas, lactantes; não misturar com } \\
\text { estimulantes e bebidas alcoólicas;menores de } 18 \\
\text { anos. }\end{array}$ \\
\hline 7 & $\begin{array}{l}30 \text { cápsulas / } \\
30 \mathrm{mg}\end{array}$ & 1 cápsula/ dia & Cafeína - $420 \mathrm{mg}$ & $\begin{array}{c}\text { Hipertensos, pessoas com problemas cardíacos e } \\
\text { comproblemas de } \\
\text { ansiedade. }\end{array}$ \\
\hline 8 & $\begin{array}{l}60 \text { cápsulas / } \\
\text { 30mg }\end{array}$ & 2 cápsulas/ dia & Cafeína - $300 \mathrm{mg}$ & $\begin{array}{c}\text { Hipertensos, pessoas com problemas cardíacos, } \\
\text { grávidas } \\
\text { e lactantes. }\end{array}$ \\
\hline 9 & $\begin{array}{l}60 \text { cápsulas / } \\
20 \mathrm{mg}\end{array}$ & 3 cápsulas/ dia & $\begin{array}{c}\text { Cafeína anidra }-250 \mathrm{mg} \\
\text { Extrato de Chá Verde }-375 \\
\text { mg } \\
\text { Erva Mate }-200 \mathrm{mg}\end{array}$ & $\begin{array}{l}\text { Hipertensos, cardiopatas, grávidas, lactantes, } \\
\text { pessoas com problemas de insônia. }\end{array}$ \\
\hline 10 & $\begin{array}{l}30 \text { cápsulas / } \\
12 \mathrm{mg}\end{array}$ & $\begin{array}{l}1 \text { cápsula } 2 \text { vezes/ } \\
\text { dia }\end{array}$ & $\begin{array}{l}\text { Cafeína anidra }-6 \mathrm{mg} \\
\text { Chá Verde }-10 \mathrm{mg}\end{array}$ & $\begin{array}{l}\text { Hipertensos, cardiopatas, grávidas, lactantes e com } \\
\text { hipersensibilidade a uma substâncias. }\end{array}$ \\
\hline
\end{tabular}

Fonte: Autores.

Buscando atender ao que foi proposto no objetivo geral desta pesquisa, construiu-se a tabela 1 , onde constam 10 suplementos e suas respectivas composições. Partindo disso, pode-se observar que 8 suplementos continham, além da sinefrina, outras substâncias em sua composição, sendo elas: Cafeína (100 mg -420 mg), Cafeína anidra (6 mg - 250 mg), Chá verde (10 mg - $700 \mathrm{mg}$ ), Capsiate (2,5 mg), Faseolamina (200 mg), Pholia Negra (100 mg), Ioimbina (5,4 mg) e Erva Mate (200 mg). Quanto à dosagem de sinefrina, constatou-se que apenas 3 produtos apresentaram somente essa substância em sua composição, das quais suas dosagens foram: Suplemento 2 - $1600 \mathrm{mg}$; suplemento 3 - $1000 \mathrm{mg}$; suplemento 6 - 500 mg. Nos demais suplementos, a dosagem de sinefrina obteve variações entre $12 \mathrm{mg}$ e $300 \mathrm{mg}$, em virtude das demais substâncias presentes em sua formulação.

Bueno (2017) e Pinheiro (2020) explicam que, para aquelas pessoas que desejam reduzir peso, a dose máxima diária, recomendada, da sinefrina é de $5 \mathrm{mg}$ a $50 \mathrm{mg}$, sendo assim, observa-se que os suplementos que atenderam a essa recomendação foram os suplementos 7, 8, 9 e 10. Já os demais produtos apresentaram altas doses de sinefrina, fato este que pode gerar danos à saúde dos usuários. Complementando, Oliveira et al. (2017b) afirmam que a sinefrina, quando utilizada na formulação de fitoterápicos, para uso crônico, pode ser usada nas dosagens de $20 \mathrm{mg}$ até $60 \mathrm{mg}$. Porém, os autores ressaltam que quando associados a outros compostos, podem gerar efeitos adversos ao consumidor, por conta disso, recomenda-se o auxílio de profissionais habilitados para orientar quanto ao consumo dos mesmos. Entretanto, a pesquisa levantada por Alves e Capela (2019) contrapõe-se ao que Oliveira et al. (2017b) discorre sobre a dosagem recomendada da sinefrina. Eles realizaram uma pesquisa em 15 adultos, normotensos, de peso normal, os quais receberam uma dosagem de $54 \mathrm{mg}$ de sinefrina; foi verificado que, entre as primeiras 5 horas, houve um aumento significativo da PA e da frequência cardíaca, no grupo tratado 
com essa substância. Diante disso, Alves e Capela (2019) concluíram que, consumida em altas dosagens, a sinefrina pode apresentar um risco em potencial à saúde do usuário, principalmente, por ser um estimulante dos receptores $\alpha 1$-adrenérgicos, os quais resultam em vasoconstrição e aumento da PA. Corroborando com os autores supracitados, Schmitt (2012), Figueira (2014), Zemolin (2015) e Do Nascimento et al. (2017), afirmam também que, os efeitos colaterais mais presentes relacionados ao uso da sinefrina, são os que lesionam o sistema cardiovascular, gerando dores no peito, aumento da PA e da frequência cardíaca. Além disso, pode provocar quadros de ansiedade e danos no fígado, também. Assim sendo, contesta-se a hipótese que afirma que a sinefrina não desenvolve efeitos adversos sobre a PA. Por conseguinte, visando pontuar os efeitos colaterais da interação entre sinefrina e outras substâncias, observa-se que a fala de Lopes e Capela (2017) sobre a composição dos suplementos é coerente; os autores afirmam que os suplementos mais populares, isto é, mais comercializados, possuem em sua composição as seguintes substâncias: cafeína, carnitina, chá verde, ácido linoleico conjugado, forscolina, crômio, fucoxantina e sinefrina. Já na pesquisa realizada por Santos e Ramos (2018), os autores destacam o uso recorrente, também, dos seguintes componentes: capscium (mesmo que capsiate), cafeína, ioimbina e citrus aurantium. Assim como, De Oliveira et al. (2018) e Sousa et al. (2019) citam o uso da Faseolamina e Pholia Negra (conhecida também como Erva-mate), respectivamente, na formulação de suplementos para emagrecimento.

Diante disso, é inevitável afirmar que, em decorrência do culto social à magreza e estética, há uma procura desenfreada por produtos que contenham formulações consideradas emagrecedoras e principalmente, àquelas comercializadas como "naturais", pois grande parte dos usuários acreditam que tais produtos não possuem efeitos colaterais ou danos à saúde (Kaefer, 2014). Sob essa ótica e a partir das amostras coletadas da internet, identificou-se que 4 suplementos continham em sua composição a cafeína, chá verde e sinefrina. Segundo Zemolin (2015), essas três substâncias são largamente utilizadas com o objetivo de oxidar gordura, aumentar o gasto energético e realizar lipólise. Por outro lado, podem produzir alguns efeitos adversos, tais como: aumento de PA, taquicardia, tremores, vômitos, náuseas, dores de cabeça e prisão de ventre.

De acordo com Pinheiro (2020) e Preuss et al., 2013 (apud Alves \& Capela, 2019), quando associada à cafeína, a dosagem máxima diária segura de sinefrina deve ser de até $40 \mathrm{mg}$ e $320 \mathrm{mg}$ de cafeína. Diante disso, observou-se que apenas os suplementos 8, 9 e 10 estavam dentro da dosagem recomendada. Um estudo realizado em ratos, por Hansen et al. (2013), constatou que $95 \%$ dos animais sob tratamento com a sinefrina $(50 \mathrm{mg})$, não apresentaram efeitos adversos sobre a frequência cardíaca ou PA, contudo, quando foi adicionado cafeína ao composto, houve aumento destes parâmetros, apontando que, quando essas duas substâncias estão associadas, podem favorecer a ocorrência de problemas cardiovasculares. Kaefer (2014) em seus estudos verificou também, que a ação sinérgica entre sinefrina e cafeína é potencialmente perigosa às pessoas que possuem algum problema no coração, pois ambas substâncias podem produzir a arritmia, hipertensão, ataques cardíacos e acidente vascular cerebral (AVC).

A pesquisa desenvolvida por Fagundes (2016) apontou também, outros efeitos adversos na associação entre sinefrina e cafeína, assim, a autora constatou alterações nos marcadores bioquímicos e de estresse oxidativo, bem como danos hepáticos e renais, levando a considerar que tais substâncias apresentam alta toxicidade sobre o fígado. Diante dessas informações, pode-se confirmar a hipótese relacionada a associação entre sinefrina e cafeína, isto é, quando há combinação entre essas duas substâncias, há maiores chances de ocorrer o aumento da PA e também da frequência cardíaca, bem como de produzir outros efeitos, como AVC, arritmias, entre outras. Por conta disso, os suplementos 5, 7, 8, 9 e 10, apresentaram contraindicação do seu uso em pessoas hipertensas e cardiopatas. Quanto à associação da sinefrina com chá verde, não houve relatos específicos sobre a ação sinérgica de ambas substâncias. Constatou-se apenas que, segundo o Ministério da Saúde (MS), o chá verde (Camellia sinensis) apresenta potencial efeito termogênico (porém a dose recomendada é variada, isto é, não há uma dose exata para tal efeito), antioxidante, anti-inflamatória, hipocolesterolêmicas, entre outros, ajudando no tratamento de diversas doenças crônicas (Brasil, 2016). 
Por outro lado, Lopes e Capela (2017) explicam que extrato de chá verde pode aumentar o conteúdo total de cafeína ingerida nos suplementos, pois possui significativa quantidade de cafeína em sua composição. Isso significa que o chá verde, quando associado a cafeína e sinefrina, pode potencializar os efeitos sobre o organismo. Zemolin (2015) complementa com sua pesquisa que, o chá verde quando presente em formulações contendo cafeína, pode aumentar o teor desta, promovendo um efeito estimulante mais expressivo, porém, potencializando os efeitos colaterais no organismo. Em se tratando o Capsicum annuum (Capsiate), são capsaicinóides, encontrados nos compostos bioativos das pimentas vermelhas. São usados com bastante frequência como antioxidantes e termogênicos, estimulando a circulação sanguínea e digestão (Costa et al., 2019). A Ioimbina, por sua vez, é considerada um alcaloide, proveniente da Pausinystalia yohimbe. Essa substância pertence à classe dos bloqueadores alfa-adrenérgicos, sendo indicado para a impotência sexual masculina. Por outro lado, é contraindicado para pessoas que sofrem de doenças cardíacas e renais, bem como, não pode ser usada, simultaneamente, com anti-hipertensivo clonidina (Ferreira, 2020).

Em se tratando da Faseolamina, é uma substância proveniente do Phaseolus vulgaris (mais conhecido como feijão branco). Trata-se de uma proteína vegetal com ação inibidora da enzima alfa-amilase, a qual é vendida como bloqueadora de amido impedindo a degradação dos carboidratos complexos em açúcares simples (Zemolin, 2015). Um estudo realizado por De Oliveira et al. (2018) comparando a ação da faseolamina com o citrus aurantium, apontou que a primeira substância apresentou resultados mais relevantes se comparado a segunda substância. Desse modo, os autores concluíram que a faseolamina exerceu uma melhor ação no organismo, inibindo a digestão e absorção do amido, enquanto que o citrus aurantium não apresentou mudanças significativas no grupo participante da pesquisa.

Quanto à Pholia Negra (popularmente conhecida como Erva-Mate), é uma erva muito utilizada pelos indígenas, sua principal fonte é a Ilex paraguariensis, uma erva encontrada no Sul da América. Tem sido bastante utilizada para auxiliar na redução de peso, reduzindo o apetite e promovendo a queima de gorduras e calorias (Sousa et al., 2019). Assim como no chá verde, a Pholia Negra apresenta, em sua composição, certo teor de cafeína (cafeiol e ácido cafeico), contudo na literatura pesquisada, não houve relatos sobre efeitos adversos decorrentes da associação entre essa substância, a cafeína e sinefrina (Sousa et al., 2019).

Partindo das análises realizadas, com base nos artigos verificados, não houve fatos comprovados de que a sinefrina associada ao capsiate, a ioimbina, a faseolamina e a Pholia Negra, produzissem reações adversas no organismo de seus usuários. No entanto, a cafeína foi a que mais apresentou efeitos colaterais quando associada à sinefrina, principalmente, no sistema cardiovascular. Diante das informações levantadas, cabe contestar a terceira hipótese desta pesquisa, a qual afirma que os suplementos são saudáveis se neles constar a quantidade segura de mg do produto, pois, de acordo com Pinheiro (2020), mesmo os suplementos que são aprovados pela ANVISA podem causar sérios efeitos colaterais por usuários que apresentam algum dos fatores de risco, principalmente, aquelas com doenças cardiovasculares. Isso se comprova através dos suplementos 8, 9 e 10, que, mesmo apresentando uma dosagem equilibrada de seus componentes, ainda sim, havia contraindicação para pessoas com problemas cardíacos. Pinheiro (2020) também auxilia que, antes de consumir tais produtos, é necessário se ter auxílio de um profissional, podendo este ser um nutricionista, farmacêutico ou médico. Todavia, a maioria dos usuários de suplementos termogênicos utilizam tais produtos sem uma orientação profissional adequada, fato esse comprovado na pesquisa feita por Santos e Ramos (2018), a qual foi realizada na cidade de Santarém/PA, com 102 participantes, divididos em grupo dos praticantes de atividade física e grupo dos sedentários. Do grupo dos sedentários, $60 \%$ consumiam termogênicos, porém $80 \%$ destes, não sabiam explicar a quantidade ingerida. O estudo revelou também que, cerca de $65 \%$ dos participantes faziam o uso por conta própria, mas sob influência da mídia; apenas 5\% desses participantes tinham indicação de um nutricionista.

Tão importante quanto o acompanhamento de um nutricionista, Santos e Ramos (2018) defendem que o profissional mais apto para realizar esse acompanhamento a usuários de suplementos, é o farmacêutico, pois ele dispõe de uma gama de 
conhecimento sobre como essas substâncias podem agir no organismo humano, sendo possível orientar quanto ao horário correto de uso, alertar sobre as interações com outras substâncias e nortear quanto aos riscos do uso indiscriminados desses produtos.

Oliveira et al. (2017a) e Oliveira et al. (2017b) corroboram que, para consumo de suplemento termogênicos, se faz necessário o acompanhamento de um profissional habilitado, que conheça sobre os produtos, sobre seus efeitos no organismo, de modo a não colocar em risco a saúde do usuário. Além disso, esse profissional pode, não só orientar quanto ao uso de tais produtos, como também, orientar sobre a associação com atividades físicas e alimentação balanceada.

\section{Considerações Finais}

A Sinefrina, quando utilizada em doses fora do recomendado, pode provocar alterações no sistema cardiovascular, tais como, aumento da PA, aumento da frequência cardíaca, e ainda, provoca alterações no SNC, levando a quadros de ansiedade, agitação e tremores no corpo. Quando associada à cafeína, a sinefrina pode provocar riscos ainda maiores no sistema cardiovascular, como por exemplo, arritmias, ataques cardíacos e acidente vascular cerebral. Suplementos a base de sinefrina não são saudáveis, principalmente, quando associada à cafeína e quando consumida em doses elevadas. A Sinefrina não é indicada para pessoas que sofrem com algum tipo de problema cardiovascular. Recomenda-se que, antes de consumir qualquer tipo de suplemento, é necessário o acompanhamento de um profissional habilitado para orientar quantos aos efeitos (benéficos ou não) que o produto pode trazer ao organismo, os perigos quanto ao uso indiscriminado e pode também, sugerir outras formas de atingir o objetivo desejado, minimizando o risco de efeitos colaterais por ingestão desses suplementos. Os consumidores de suplementos termogênicos, devem estar informados acerca dos riscos para a saúde associados ao consumo da sinefrina, pelo que devem contactar um profissional de saúde antes de iniciar a sua toma. Dessa forma, são necessários mais estudos futuros que possam garantir a segurança e eficácia de suplementos termogênicos que contém sinefrina.

\section{Referências}

ANVISA. (2018). RDC n⿳ 243, de 26 de julho de 2018: dispõe sobre os requisitos sanitários dos suplementos alimentares. Agência Nacional de Vigilância Sanitária - ANVISA. Diário Oficial da União, Ministério da Saúde, 2018.

Alves, M. C. R., \& Capela, J. P. (2019). Suplementos alimentares para emagrecimento contendo sinefrina: riscos e toxicidade. Acta Portuguesa De Nutrição, $16,36-46$.

Andressa, E. (2015). Dicas fitness: falando de boa forma e saúde. Phorte.

Aquino, I. (2010). Efeito genotóxico da Artemisinina e do Artesunato em células de mamíferos. 2010.81 f. Dissertação (Mestrado em Biologia Geral e Aplicada). Instituto de Biociências. Universidade Estadual Paulista. Botucatu, São Paulo.

Associação Brasileira de Produtos Nutricionais - ABENUTRI. (2018). Pesquisa revela crescimento de $15 \%$ em 2018 no seguimento de suplementos esportivo no país. http://www.abre.org.br/noticias/abenutri- preve-crescimento-de-15-em-2018-no-segmento-de-suplementos-esportivos-no- pais/.

IHRSA. (2018). Grandes oportunidades e resultados ainda maiores. Associação Internacional de Fomento ao Universo de Saúde e Exercícios - IHRSA. http://hub.ihrsa.org/brasil/ihrsa-2018-grandes-atracoes-e- resultados-ainda-maiores.

Bacurau, R. F. (2007). Nutrição e suplementação esportiva. (5a ed.), Phorte.

Beles, J. (2014). As plantas medicinais que emagrecem. Lua de Papel.

Brasil. Ministério da Saúde. (2010). Agencia Nacional de Vigilância Sanitária. Resolução - RDC nº 18 , de 27 de abril de 2010 : dispõe sobre alimentos para atletas. http://bvsms.saude.gov.br/bvs/saudelegis/anvisa/2010/res0018_27_04_2010.html.

Brasil. Ministério da Saúde. (2016). Desmistificando dúvidas sobre alimentação e nutrição: material de apoio para profissionais de saúde. Ministério da Saúde, Universidade Federal de Minas Gerais. - Brasília: Ministério da Saúde.

Bueno, J. (2017). Sinefrina: saiba tudo sobre o estimulante que seca gordura. Ciência e Saúde. https://br.blastingnews.com/ciencia- saude/2017/10/sinefrinasaiba-tudo-sobre-o-estimulante-que-seca-gordura- 002060831.html.

Costa, N. M., Raizel, R., Santini, E., \& Reis Filho, A. D. dos. (2012). Suplementos alimentares para o emagrecimento: eficácia questionável. RBNE - Revista Brasileira De Nutrição Esportiva, 6 (31). http://www.rbne.com.br/index.php/rbne/article/view/212 
Costa, K.C., Rios, L. J. S., Reis, I. M. A., \& Cova, S. C. (2020). O uso de fitoterápicos e plantas medicinais em processo de redução de peso: analisando prescrições nutricionais. Brazilian Journal of Development, 6 (1), 3484-3504. 10.34117/bjdv6n1-252

De Oliveira, A. P., Brasil e Bernardes, A. C., Fernandes, F. L. F., \& Tiengo, A. (2018). Avaliação dos efeitos de fitoterápicos termogênicos em parâmetros antropométricos de pacientes com sobrepeso e obesidade. RBONE - Revista Brasileira De Obesidade, Nutrição E Emagrecimento, 11(68), 667-676. http://www.rbone.com.br/index.php/rbone/article/view/626

Do Nascimento, C., Piloto, J., \& Tiyo, R. (2017). Nutracêuticos para o emagrecimento: uma revisão. Revista uningá review, 29 (2). http://revista.uninga.br/index.php/uningareviews/article/view/1955

Fagundes, A. C. (2016). Análise toxicológica de suplementos alimentares e compostos emagrecedores contendo salicina, efedrina, p-sinefrina e cafeína. $73 \mathrm{f}$. Dissertação (Mestrado em Ciências Farmacêuticas). Faculdade de Farmácia. Universidade Federal do Rio Grande do Sul.

Ferreira, A. O. (2020). Ioimbina: vasodilatador. Infinity pharma. https://infinitypharma.com.br/uploads/insumos/pdf/i/ioimbina.pdf.

Figueira, C. F. P. (2014). Toxicidade associada a plantas medicinais no emagrecimento. Dissertação (Mestrado em Ciências Farmacêuticas). Faculdade de Farmácia. Universidade de Lisboa.

Galvão, T. F., \& Pereira, M. G. (2014). Revisões sistemáticas da literatura. Revista Epidemiologia e Serviços de Saúde, 23 (1), 183-184.

Gindri, A. L., De Souza, L. B., Cruz, R. C., Boligon, A. A., Machado, M. M., \& Athayde, M. L. (2014). Genotoxic evaluation, secondary metabolites and antioxidant capacity of leaves and roots of Urera baccifera Gaudich (Urticaceae). Natural product research, 28 (23), 2214-2216.

Hansen, D. K., George, N. I., White, G. E., Abdel-Rahman, A., Pellicore, L. S., \& Fabricant, D. (2013). Cardiovascular toxicity of Citrus aurantium in exercised rats. Cardiovascular toxicology, 13(3), 208-219.

Kaefer, C. L. (2014). Sinefrina: desenvolvimento e validação de método indicativo da estabilidade e avaliação da toxicidade em extrato seco de Citrus aurantium L. 68 f. (Dissertação de Mestrado). Programa de Pós-graduação em Ciências Farmacêuticas, Universidade Federal do Pampa.

Lopes, M. D. M. (2016). Suplementos alimentares termogênicos contendo cafeína: riscos para saúde. 42 f. Monografia (Licenciatura em Ciências da Nutrição). Faculdade Ciências da Saúde. Universidade Fernando Pessoa.

Lopes, M. D. M., \& Capela, J. P. (2017). Estudo comparativo da composição dos suplementos alimentares termogênicos contendo cafeína disponíveis em Portugal. Acta Portuguesa de Nutrição. 10 (10), 24-36.

Miranda, G. M. D., Mendes, A. C. G., \& Silva, A. L. A. (2016). O envelhecimento populacional brasileiro: desafios e consequências sociais e atuais futuras. Revista Brasileira de Geriatria, 19 (3), 507- 519.

Muraro, C.R., \& Saldanha, R.P. (2016). Uma revisão de literatura sobre o uso de termogênicos e seus efeitos no organismo. Revista Perspectiva, Ciência e Saúde, 1 (1), 85- 96.

Preuss, H., Miller, H., Stohs, S., \& Kaats, G. (2013). Health Canada Synephrine Octopamine Caffeine HRA 2011-05-16 approved 2011-05-24[1].

Oliveira, A. B. de, Mapurunga Filho, J. N., \& Aguiar Melo, M. C. (2017). Consumo de suplementos termogênicos e seus efeitos adversos por clientes de uma loja de Nutrição Esportiva de Fortaleza-CE. RBNE - Revista Brasileira De Nutrição Esportiva, 11 (62), 160-167. http://www.rbne.com.br/index.php/rbne/article/view/749

Oliveira, T. W. N., Teixeira, S. A., Oliveira, V. A., Castro, A. N., Martins, M. R., \& Medeiros, S. R. A. (2017b). Laranja amarga (Citrus aurantium) como coadjuvante no tratamento da obesidade. Revista Saúde e Ciência. 6 (1), 114- 126. doi.org/10.35572/rsc.v6i2.171

OMS - Organização Mundial da Saúde. (2018). Mais de 1,4 bilhão de adultos correm risco de desenvolver doenças por inatividade física em todo o mundo. Organização Pan-Americana da Saúde (OPAS). https://www.paho.org/bra/index.php?option=com_content\&view=article\&id=5753:mai s-de-1-4-bilhao-deadultos-correm-risco-de-desenvolver-doencas-por-inatividade- fisica-em-todo-o-mundo\&Itemid=839.

Pacheco, J. J. (2017). Prevalência no uso de suplementos alimentares por frequentadores de academias em diferentes regiões do Brasil. Revista UNIESP, 4 (11), $12 \mathrm{p}$.

Peçanha, A. M. M., Frigeri, R., \& Silva Filho, J. N. (2017). Suplementos termogênicos: evidências sobre a sua eficácia na redução da gordura corporal. RBNE - Revista Brasileira De Nutrição Esportiva, 11 (65), 544-553. http://www.rbne.com.br/index.php/rbne/article/view/819

Pinheiro, P. (2020). Termogênicos: riscos e efeitos colaterais. Revista Medicina e Saúde. https://www.mdsaude.com/obesidade/termogenicos/

Ponsoni, L. (2019). Mercado de suplementos cresceu 12\% no Brasil em 2018. Vida Fit. https://jc.ne10.uol.com.br/blogs/vidafit/2019/04/10/mercado-desuplementos-cresceu-12-no-brasil-em-2018/.

Sampaio, R. F., \& Mancini, M. C. (2007). Estudos de revisão sistemática: um guia para síntese criteriosa da evidência científica. Brazilian Journal of Physical Therapy, 11 (1), 83- 89. doi.org/10.1590/S1413-35552007000100013

Santos, D. A., \& Ramos, L. F. P. (2018). Avaliação do conhecimento entre praticantes de atividade física e sedentários sobre os efeitos fisiológicos e adversos dos suplementos termogênicos. RBNE - Revista Brasileira De Nutrição Esportiva, 12 (75), 875-883. http://www.rbne.com.br/index.php/rbne/article/view/1158

Schmitt, G. C. (2012). Análise química e toxicológica de suplementos alimentares e compostos emagrecedores contendo p-sinefrina associada à efedrina, salicina e cafeína. Tese (Doutorado em Ciências Farmacêuticas) - Universidade Federal do Rio Grande do Sul.

Sousa, D. M. D., Sousa, M. D., Macedo, J. L., Silva, S. S., Silva, R. R. C., Nascimento, L. L. B., Santos, L. S., \& Miranda Junior, R. N. C. (2019) Fitoterápicos utilizados para perda de peso comercializados em farmácias. Research, Society and Development, 8 (4), 01-15.

Zemolin, G. M. (2015). Análise de estimulantes em suplementos alimentares e produtos naturais a base de plantas comercializadas para fins de emagrecimento no Brasil. 115 f. Dissertação (Mestrado em Ciências Farmacêuticas). Centro de Ciências da Saúde. Universidade Federal de Santa Maria. 